\title{
OBSERVATIONS ON THE DARKROOM TEST AND ITS MECHANISM*
}

\author{
BY \\ WALLACE S. FOULDS \\ From the Glaucoma Clinic, Institute of Ophthalmology, University of London \\ Director of Research: Sir Stewart Duke-Elder
}

THE RISE in ocular tension after a period in the dark first noted by Grönholm (1910) was later developed as a provocative test by many different workers (Seidel, 1920; Serr, 1928; Sallmann, 1930; Ohm, 1936; Ross, 1953; Higgitt, 1954).

Conflicting opinions on the value of the darkroom test have been expressed, Higgitt finding that 78 per cent. of his cases of "congestive glaucoma" gave a positive rise in ocular tension with the test, while Leydhecker (see DukeElder, 1955) found that only 11 per cent. of his suspected congestive cases with narrow anterior chamber angles did so. Leydhecker wondered what should constitute a positive test, feeling that the rise of $9 \mathrm{~mm}$. $\mathrm{Hg}$ suggested by Higgitt was probably somewhat low, and noting that no statistical analysis of the change in ocular tension to be found in normal eyes with the test had yet been published.

While some of the negative results with this test which have been reported in the past have undoubtedly been due to its use in cases of chronic simple glaucoma, there is no doubt that, even in cases of known closed-angle glaucoma, negative results with the darkroom test are not uncommon.

The present study of the darkroom test was originally undertaken so that the results might be compared statistically with those of the darkroom outflow test, details of which have already been published (Foulds, 1956). Several points of interest which might help to explain the mechanism of angle closure have however emerged, and these are presented here.

\section{Material}

The results reported are all of tests performed at the Institute of Ophthalmology as part of the routine work of the Glaucoma Clinic, the method used being similar to that described by Higgitt (1954). The eyes of the patient to be tested were anaesthetized by a drop of 1 per cent. amethocaine hydrochloride in each, and a measurement of the ocular tension was made with a standard Schiötz X-tonometer. The patient was then placed in the darkroom for one hour and at the end of this period a further measurement of the ocular tension was made with the same instrument as before. Both the initial and final measurements were made under normal room lighting. 
The analysis is based on the results of the test on a series of 57 normal cases and on 108 cases of clinically diagnosed closed-angle glaucoma. Before being assigned to the control series, the normal cases were all extensively studied; the case history was taken, the peripheral and central visual fields were recorded, and gonioscopy, tonometry, and an outflow test were performed on each. Only persons with no sign or symptom suggestive of glaucoma and only those without narrow anterior chamber angles were included in this group. In the closed-angle glaucoma series, all cases had some recognizable clinical stigma of the disease and all had narrow anterior chamber angles. From each group only one eye chosen at random from each patient tested was included in the series to be analysed, so that the similarity of fellow eyes might not minimize the variance of the series.

In order that the two series of cases should be comparable except with regard to the presence or absence of closed-angle glaucoma, it was necessary to ensure that the age and sex distribution within and between the two series should be similar. The proportion of males to females and the mean age of each group were calculated for the two series of cases, and no significant differences were found between the two series in these respects (Tables I and II).

TABLE I

COMPARISON OF SEX DISTRIBUTION IN 57 NORMAL CASES AND 108 CASES OF CLOSED-ANGLE GLAUCOMA

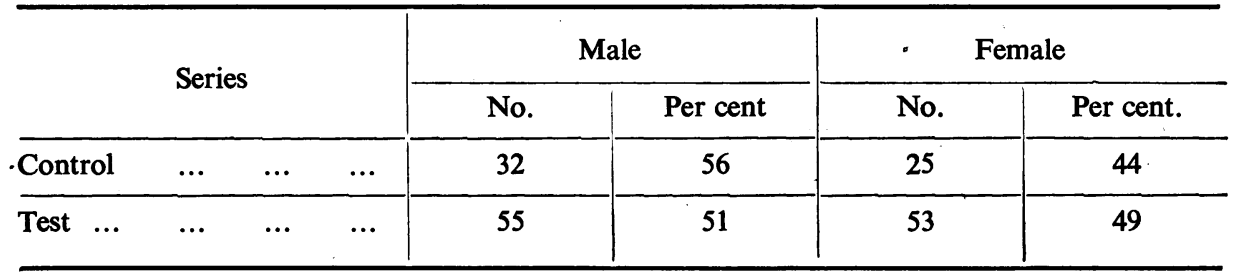

$x^{2}=0.406 ; \quad n=1 ; \quad P=>0.50$.

TABLE II

COMPARISON OF AGE DISTRIBUTION IN 57 NORMAL CASES AND 108 CASES WITH CLOSED-ANGLE GLAUCOMA

\begin{tabular}{|c|c|c|c|c|c|c|}
\hline \multirow{2}{*}{\multicolumn{2}{|c|}{ Series }} & \multicolumn{2}{|c|}{ Mean Age (yrs) } & \multirow{2}{*}{$\begin{array}{l}\text { Comparison of Mean } \\
\text { Ages of Males } \\
\text { and Females }\end{array}$} & \multirow{2}{*}{$\begin{array}{c}\text { Total } \\
\text { Mean Age } \\
\text { (yrs) }\end{array}$} & \multirow{2}{*}{$\begin{array}{l}\text { Comparison of Total } \\
\text { Mean Age in Control } \\
\text { and Test Series }\end{array}$} \\
\hline & & Male & Female & & & \\
\hline Control & $\ldots$ & $\begin{array}{c}55 \cdot 7 \\
( \pm 13 \cdot 0)\end{array}$ & $\begin{array}{c}57 \cdot 8 \\
( \pm 10 \cdot 2)\end{array}$ & $\begin{array}{l}t=1 \cdot 11 \\
n=55 \\
P=>0 \cdot 10\end{array}$ & $\begin{array}{c}56 \cdot 8 \\
( \pm 11 \cdot 8)\end{array}$ & \multirow{2}{*}{$\begin{array}{l}t=0.433 \\
n=163 \\
P=>0.10\end{array}$} \\
\hline Test & $\ldots$ & $\begin{array}{c}57 \cdot 4 \\
( \pm 10 \cdot 4)\end{array}$ & $\begin{array}{c}57 \cdot 8 \\
( \pm 11 \cdot 8)\end{array}$ & $\begin{array}{l}t=0 \cdot 18 \\
n=106 \\
P=>0 \cdot 10\end{array}$ & $\begin{array}{c}57 \cdot 7 \\
( \pm 11 \cdot 0)\end{array}$ & \\
\hline
\end{tabular}

Table I shows the sex distribution of the two series; on analysis by a $\chi^{2}$ test, there is no significant difference between the control and test series in regard to sex composition $\left(\chi^{2}=0.406 ; n=1 ; P=>0.50\right)$. Table II shows the age distribution; the two series are comparable in this respect also. In the control series the mean age of the males ( $55.7 \mathrm{yrs}$ 
$\pm 13.0)$ does not differ significantly from that of the females $(57 \cdot 8 \mathrm{yrs} \pm 10 \cdot 2)(t=1 \cdot 11$; $n=55 ; P=>0 \cdot 10)$. In the test series the mean age of the males $(57 \cdot 4 \mathrm{yrs} \pm 10 \cdot 4)$ is not significantly different from that of the females $(57.8$ yrs $\pm 11 \cdot 8)(t=0.18 ; n=106$; $P=>0 \cdot 10)$. In addition the mean age of all cases in the control series $(56 \cdot 8 \mathrm{yrs} \pm 11 \cdot 8)$ is not significantly different from that in the test series $(57.6$ yrs \pm 11.0$)(t=0.433$; $n=163 ; P=>0 \cdot 10$ ).

\section{Results of Investigation}

The effect of darkness on the ocular tension of normal eyes was first studied, as it has been stated that there is a tendency for the test to produce a small rise in tension in such eyes (Duke-Elder, 1940; Higgitt, 1954).

In the present series a rise in ocular tension of $7 \mathrm{~mm}$. $\mathrm{Hg}$ (Schiötz) was found in some normal eyes. The mean rise was small $(+0.97 \mathrm{~mm} . \mathrm{Hg} \pm 2.54)$ but statistically significant, as can be seen by comparing this value with the expected value of zero by Student's " $t$ " test. $\dagger$ This small mean rise reflects the fact that 36 per cent. of the normal eyes tested showed a rise in ocular tension with the test, while only 9 per cent. showed a fall.

In the known closed-angle series, a well-marked rise in ocular tension occurred with the test (mean $+11 \cdot 12 \mathrm{~mm}$. $\mathrm{Hg} \pm 12 \cdot 08)$. A " $t$ " test shows that this mean rise differs significantly from that in the normal series. $\ddagger$

From the behaviour of the normal eyes it is possible to determine what rise in ocular tension should be regarded as a positive test. A rise of more than three times the standard deviation of the mean rise in the normal series could reasonably be regarded as a positive result, for such a rise could occur by chance less than once in a hundred cases. Three times this standard deviation (2.54) gives a rise of $7.62 \mathrm{~mm}$. $\mathrm{Hg}$ above the mean rise found in the normal series $(+0.97 \mathrm{~mm}$. $\mathrm{Hg})$, making a positive result a rise in ocular tension of at least $+8.6 \mathrm{~mm}$. Hg. If 95 per cent. confidence limits are applied to the mean rise in the normal series with the test, it is found that a positive result could lie between +7.8 and $+9.4 \mathrm{~mm}$. $\mathrm{Hg}$.

This is in close agreement with the rise of $+9 \mathrm{~mm}$. $\mathrm{Hg}$ proposed by Higgitt as the measure of a positive result, although it would seem that the actual figure might in fact be a little lower than this author thought.

\section{Value of the Darkroom Test}

Of the 108 eyes with known closed-angle glaucoma, only 56 (51.9 per cent.) showed a rise of more than $8 \mathrm{~mm}$. $\mathrm{Hg}$, and of these seventeen had initial tensions already above "normal" limits (i.e. greater than $31 \mathrm{~mm} . \mathrm{Hg}$ ).

In order to determine whether there was a clear demarcation between the results in the control and glaucomatous series, the results in each series were classified according to the change in tension produced by the test (from $-7 \mathrm{~mm}$. $\mathrm{Hg}$ to $+60 \mathrm{~mm}$. $\mathrm{Hg}$ in 3-mm. steps); the number of results in each group was expressed as a percentage of the total number of tests in each 
series. These results are represented graphically in Fig. 1, which shows that the two series overlap considerably, so that in many cases the test does not clearly separate the normal from the abnormal.

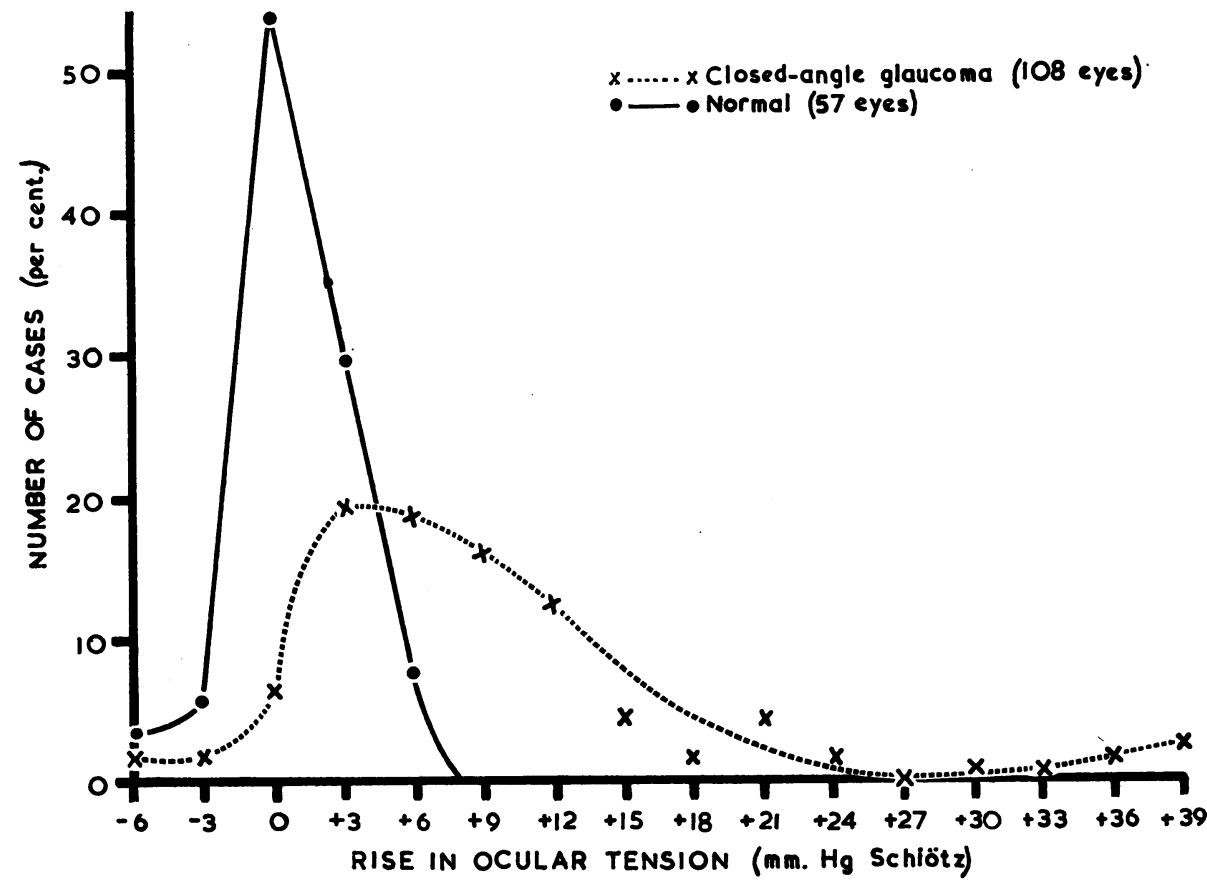

FIG. 1.-Graph to show distribution of 57 normal eyes and 108 eyes with closed-angle glaucoma in relation to the change in ocular tension produced by the darkroom test. There is considerable overlap between the normal and glaucomatous results.

To establish whether the rise in ocular tension with the darkroom test in cases of closed-angle glaucoma was influenced at all by the ocular tension at the start of the test, the cases of closed-angle glaucoma were divided into groups according to the initial tension, and the mean final tension was determined for each group. When the mean final tension in these cases was plotted against the initial tension, it was found that for initial tensions of up to $25 \mathrm{~mm}$. $\mathrm{Hg}$ and over $30 \mathrm{~mm}$. $\mathrm{Hg}$ the test appeared to produce a mean increase in ocular tension of the order of $10 \mathrm{~mm}$. $\mathrm{Hg}$ (Fig. 2, overleaf). The mean rise in tension in the group with an initial tension of 26 to 28 $\mathrm{mm} . \mathrm{Hg}$, however, was seen to be unexpectedly large $(+26 \cdot 1 \mathrm{~mm} . \mathrm{Hg})$. This suggested that positive results might be more frequently found in eyes with an initial tension in the region of $28 \mathrm{~mm}$. $\mathrm{Hg}$ than in those with initial tensions above or below this level. To determine whether this was so, the proportion of positive results with the darkroom test occurring in groups of cases starting at different initial tensions was calculated for the cases of closed-angle glaucoma, and it was found that this proportion rose from approximately 45 per cent. of cases with an initial tension below $22 \mathrm{~mm}$. $\mathrm{Hg}$ to 71 per cent. of those with 


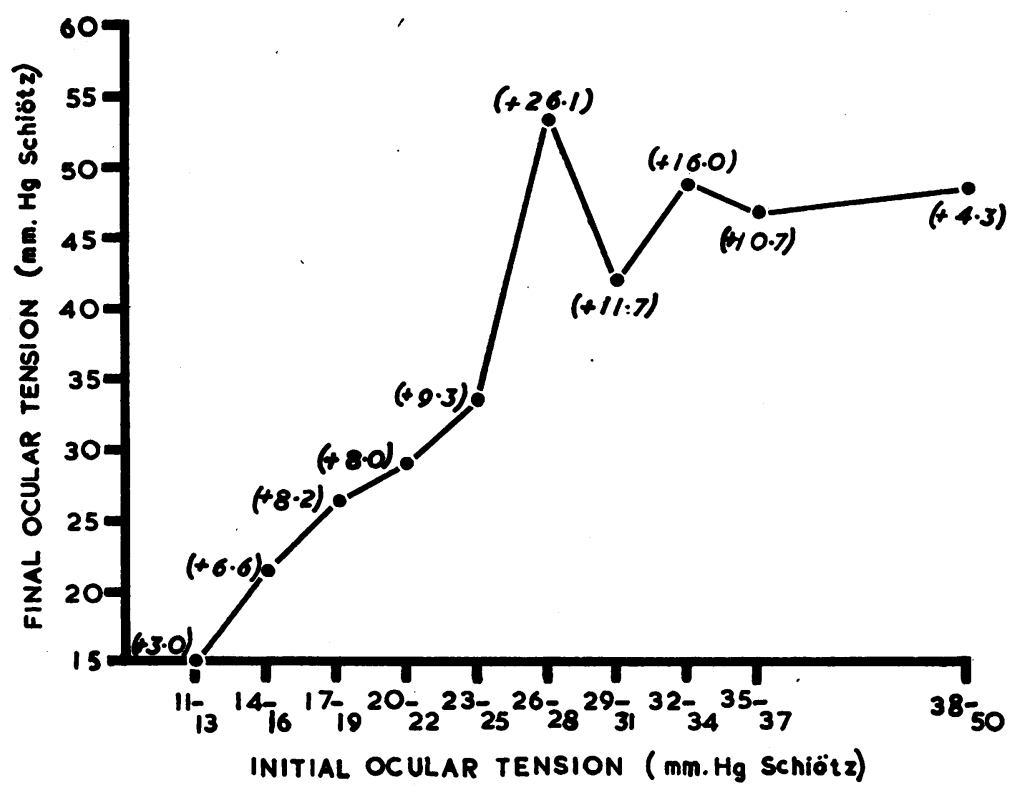

FIG. 2.-Graph to show relationship between initial and final ocular tensions of 108 eyes with closed-angle glaucoma submitted to the darkroom test. The rise in tension from an initial level of $26-28 \mathrm{~mm}$. $\mathrm{Hg}$ is greater than that from any other initial ocular tension.

The figures in brackets represent mean changes in ocular tension.

an initial tension of from $26-28 \mathrm{~mm}$. $\mathrm{Hg}$, but fell again in cases with an initial tension that was higher still (Fig. 3).

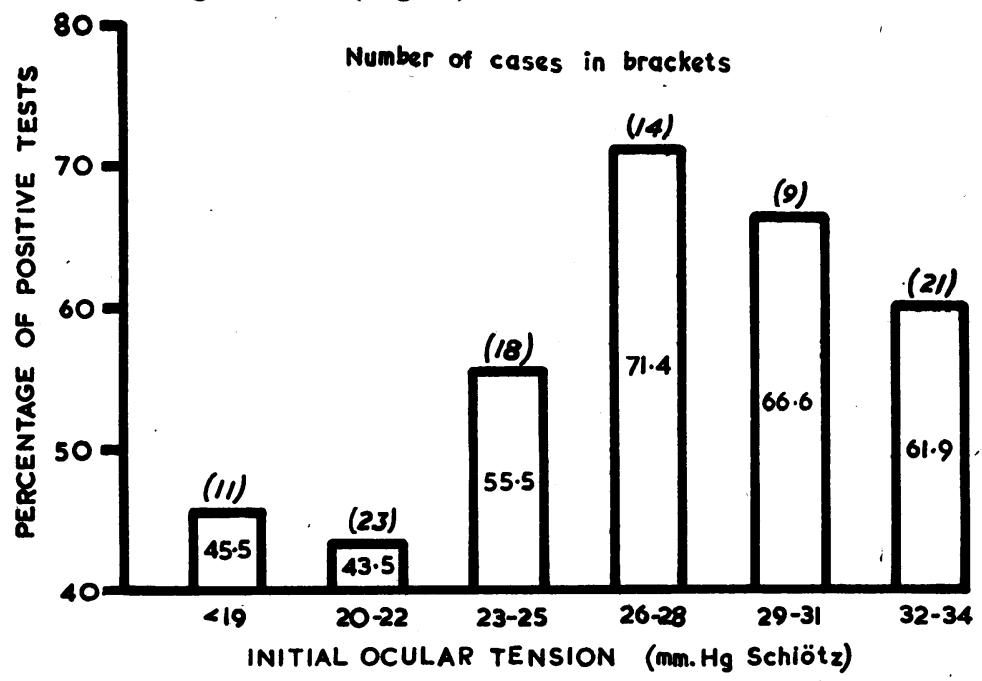

Fig. 3.-Comparison of incidence of positive darkroom tests in eyes with closed-angle glaucoma at different initial tension levels. The greatest number of positive tests occurs in the group with an initial ocular tension of 26-28 $\mathrm{mm} . \mathrm{Hg}$.

To establish whether these differences were real, the number of eyes showing 
a rise of more than $8 \mathrm{~mm} . \mathrm{Hg}$ from an initial tension of less than $25 \mathrm{~mm} . \mathrm{Hg}$ was compared by a $\chi^{2}$ test with the number showing a similar rise from an initial tension of $26-30 \mathrm{~mm}$. Hg (Table III, below); 23 out of 32 tests on eyes with an initial tension of $26-30 \mathrm{~mm}$. Hg showed a rise of more than $8 \mathrm{~mm}$. $\mathrm{Hg}(71.9$ per cent.) compared with seventeen out of 41 tests where the initial tension was below $25 \mathrm{~mm}$. $\mathrm{Hg}(41.5$ per cent.). The difference between these groups is significant.*

TABLE III

COMPARISON OF RESULTS OF DARKROOM TEST ON EYES WITH CLOSED-ANGLE GLAUCOMA AND DIFFERING INITIAL TENSION LEVELS

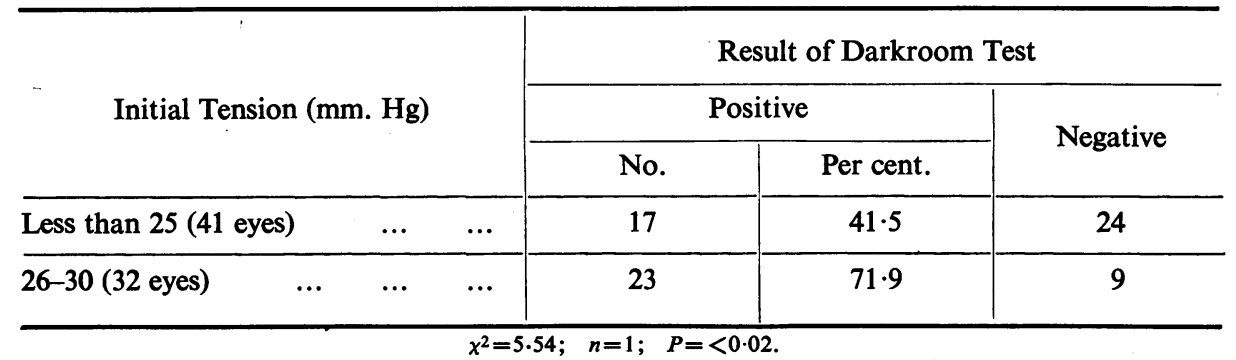

It has already been noted that the mean rise in tension with the darkroom test in eyes with closed-angle glaucoma was greater where the initial tension was in the region of $28 \mathrm{~mm} . \mathrm{Hg}(+26 \cdot 1 \mathrm{~mm}$. $\mathrm{Hg})$ than from any other initial tension, where the rise was nowhere greater than $+16 \mathrm{~mm}$. $\mathrm{Hg}$ (Fig. 1). To determine whether this large mean rise in tension in the first group was significantly different from that occurring in the other groups, the mean rise in all cases with initial tensions of from $26-30 \mathrm{~mm} . \mathrm{Hg}(+23 \cdot 7 \mathrm{~mm} . \mathrm{Hg} \pm 29 \cdot 8)$ was compared with the mean rise from all other initial tensions together $(+8.6 \mathrm{~mm}$. $\mathrm{Hg} \pm 8 \cdot 18)$. A " $t$ " test shows that the former mean rise in tension, differs significantly from the latter. $\dagger$ As this might merely mirror the fact that the group of eyes with low initial tensions had a smaller proportion of positive results than the other, the effect of the initial tension level on the magnitude of the rise produced by the test was calculated for the cases of closed-angle glaucoma which gave a positive result. Of 54 eyes showing a rise in tension of more than $8 \mathrm{~mm}$. $\mathrm{Hg}$ ten had an initial tension of from 26-28 mm. $\mathrm{Hg}$, while $44 \mathrm{had}$ an initial tension either above or below this. The mean rise in tension for the former group was $34.8 \mathrm{~mm} . \mathrm{Hg}( \pm 15.8)$ compared with $+14.8 \mathrm{~mm}$. $\mathrm{Hg}( \pm 8.9)$ for the latter. The difference between these mean rises in tension is significant. $\ddagger$ It would appear, therefore, that, not only is the result of the darkroom test more likely to be positive where the initial tension in the tested eye is in the region of $28 \mathrm{~mm}$. $\mathrm{Hg}$, but also that the actual rise in tension to be expected is greater at this initial tension than at any other. 


\section{Discussion}

In this investigation it was found that only about one half of all the cases of closed-angle glaucoma submitted to the darkroom test showed a rise in ocular tension of more than $8 \mathrm{~mm}$. $\mathrm{Hg}$.

The likelihood of an eye with closed-angle glaucoma giving a positive result with the darkroom test appeared to be related to the initial tension in that eye, and was greatest where the initial tension was in the region of 28 $\mathrm{mm} . \mathrm{Hg}$. In addition, the magnitude of the rise in tension produced by the test was also greatest at this initial ocular tension.

As has been pointed out by Barkan (1936), the angle of the anterior chamber is narrower above than below. More recently, evidence has been produced to support the view that, in cases of closed-angle glaucoma between hypertensive attacks, part of the angle of the anterior chamber is closed by iridocorneal contact, at first in the upper narrow part of the angle and later if at all in the lower, wider sector (Phillips, 1956). From the results of the darkroom test, it seems likely that an eye with a resting tension of between 26 and $30 \mathrm{~mm}$. $\mathrm{Hg}$ has already much of the filtration angle blocked either functionally or organically, and that the darkroom test in such an eye will rapidly close most of the remaining open sector to give a large rise in ocular tension. Where the angle is not so obstructed before the test, much of the time in the dark may be taken up by the gradual closure of the filtration angle from above downwards, and only if this causes the closure of a sufficient area of the filtration angle within the time allowed for the test will the tension rise appreciably. It is noteworthy that a few cases in which the result of the darkroom test was negative after one hour gave a significant rise in ocular tension after 2 hours in the dark. In addition, outflow measurements in cases of closed-angle glaucoma tend to be low where the ocular tension is above $25 \mathrm{~mm}$. $\mathrm{Hg}$, supporting the view that a certain amount of angle obstruction exists although the tension may still be within the accepted limits of normality. The great difficulty in differentiating an obstructed angle from a narrow but still functioning one, and the fact that light, by constricting the pupil, tends to re-open the filtration angle, limits the value of gonioscopy in the study of these cases; nevertheless, direct examination by this method supports the view that a positive result with the darkroom test is accompanied by complete or almost complete closure of the angle of the anterior chamber (Ross, 1953; Higgitt, 1954).

An eye with closed-angle glaucoma which shows a tension of over $25 \mathrm{~mm}$. $\mathrm{Hg}$ may be regarded as being in an unstable state and liable to develop an acute rise in tension. If this is so, it follows that an eye under treatment with miotics for closed-angle glaucoma which frequently has a tension in the upper reaches of normality may in fact be developing organic occlusion of the angle and would be better treated surgically.

From what has been said, it would appear that in the early case of closedangle glaucoma, the result of the darkroom test is more likely to be negative 
than positive, and that, though a positive result is of course of great value in such a case, a negative result does not in any way rule out the existence of the disease.

The fact that definite though small rises in ocular tension occur in some normal eyes is of great interest. In the control cases described above angle closure is most unlikely to have occurred with the test, as none of the control eyes had a narrow angle; nor did gonioscopy show angle closure in those normal eyes examined after the test. It has been shown in addition (Foulds, 1956) that there is no significant alteration in the facility of aqueous outflow in normal eyes during the darkroom test. It would appear therefore that this rise in tension in the normal eye is due to some change either in the rate of aqueous inflow or in the volume of blood in the uvea, and that presumably, in a case of closed-angle glaucoma giving a positive result, part of the rise in tension may be due to this factor as well as to closure of the angle of the anterior chamber.

\section{Summary.}

A statistical analysis of the results of the darkroom test on a control series of 57 normal eyes and a test series of 108 eyes with closed-angle glaucoma is presented.

A positive result is regarded as a rise in ocular tension of more than $8.5 \mathrm{~mm}$. Hg.

A positive result is more likely to occur where the initial tension is $25-30 \mathrm{~mm}$. $\mathrm{Hg}$ than where it is below this figure, and similarly the magnitude of the resulting increase in tension is greatest when the initial tension level is $25-30 \mathrm{~mm}$. Hg.

In early closed-angle glaucoma a negative result occurs more often than a positive one.

A small but definite rise in ocular tension occurs in normal eyes with the test.

The significance of these findings is discussed.

I wish to acknowledge the helpful criticism given by Sir Stewart Duke-Elder in the preparation of this paper.

I also wish to record my thanks to Mr. T. Tarrant of the Department of Medical Illustration, Institute of Ophthalmology, for the preparation of the line drawings.

\section{REFERENCES}

Barkan, O. (1936). Arch. Ophthal. (Chicago), 15, 101.

Duke-ELDER, S. (1940). "Text-book of Ophthalmogy", vol. 3, p. 3377. Kimpton, London.

, ed. (1955)*. "Glaucoma. A Symposium". Blackwell, Oxford.

Foulds, W. S. (1956). Trans. ophthal. Soc. U.K., 76, 83.

Grönholm, V. (1910). Arch. Augenheilk., 66, 346.

HigGIT, A. C. (1954). British Journal of Ophthalmology, 38, 242.

LEYDHECKER, W. (1955). In Duke-Elder (1955), p. 220.

OHM, G. (1936). v. Graefes Arch. Ophthal., 135, 537.

PHILlips, C. I. (1956). British Journal of Ophthalmology, 40, 136.

Ross, M. G. (1953). Amer. J. Ophthal., 36, 640.

SEIDEL, E. (1920). v. Graefes Arch. Ophthal., 102, 415.

SERR, H. (1928). Ibid., 121, 3.

Sallmann, L. (1930). Ibid., 124, 624.

* Symposium organized by the Council for International Organizations of Medical Sciences. 